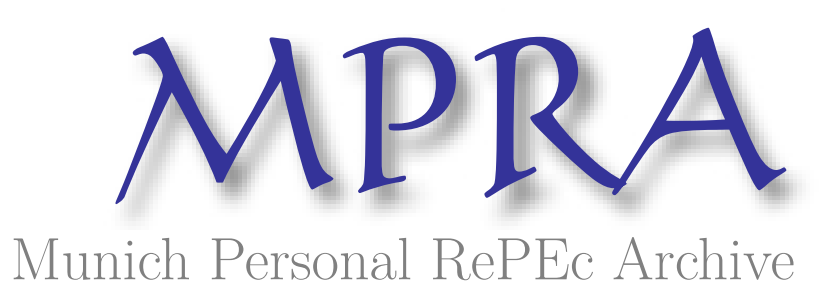

\title{
Central banks' voting contest
}

Charemza, Wojciech

Vistula University

31 May 2020

Online at https://mpra.ub.uni-muenchen.de/101205/

MPRA Paper No. 101205, posted 28 Jun 2020 12:31 UTC 


\title{
CENTRAL BANKS' VOTING CONTEST
}

\author{
WOJCIECH CHAREMZA
}

\author{
Vistula University \\ 02-787 Warsaw, Poland
}

\begin{abstract}
KEYWORDS: $\quad$ voting algorithms, monetary policy, inflation targeting, forecast
uncertainty

JEL codes: $\quad$ E47, E52, E58
\end{abstract}

June 2020

\begin{abstract}
This paper compares how effective different voting algorithms are for the decisions taken by monetary policy councils. A voting activity index is proposed and computed as the ratio of the number of all possible decisions to the total number of different combinations of decisions available to a given composition of an MPC. The voting systems considered are these used by the US Federal Reserve Board and the central banks of the UK, Australia, Canada, Sweden and Poland. In the dynamic simulation model, which emulates voting decisions, the heterogeneous agents act upon individual forecast signals and optimise a Taylor-like decision function. The selection criterion is based on the simulated probability of staying within the bounds that define the inflationary target. The general conclusion is that the voting algorithm used by the Bank of Sweden is the best given the criteria applied, especially when inflation is initially outside the target bounds. It is observed that a decrease in inflation forecast uncertainty, which is inversely proportional to the correlation between the forecast signals delivered to members of the monetary policy board, makes the voting less effective.
\end{abstract}

\section{ACKNOWLEDGEMENT}

This research has been financed by the National Science Centre in Poland, Opus 8 project 2018/29/B/HS4/01462, Construction and testing of country-specific measures of economic uncertainty. I'm grateful to Robin Hazlehurst and Ryszard Kokoszczyński for their insightful comments and suggestions. 


\section{INTRODUCTION}

Most independent central banks decide on their monetary policy by voting within a decision body usually called the monetary policy council (or board, or board of governors, or something similar), abbreviated here as MPC. The theory and practice of voting as applied in central banks has been a focus of research for some time. The recent literature concentrates particularly on the predictive power of voting records (see Horváth and Jonášová, 2015), voting transparency (Gersbach and Hahn, 2009), the efficiency and consistency of voting schemes (Gersbach and Pahl, 2009; Sosnowska, 2013), the predictability of voting results (Sirchenko, 2011; Ribon, and Ruge-Murcia, 2014; Horváth, Šmídková and Zápal 2016) and other such topics.

This paper focuses on the rather narrow, and apparently unresearched, topic of the volatility of the voting algorithms applied by different central banks. It is well known that overactive monetary policy might well result in destabilisation (e.g. Akram, Bärsden, and Eithreim, 2006; Charemza and Ladley, 2016), while a constantly passive policy might be no policy at all. It should be stressed that this paper is not about the timing of monetary decisions like Olivei and Teeyro (2007) and Choi, Eisenbach, and Yorulmazer (2016) are. Rather it considers cases where different central banks given the same set of extraneous information might take different decisions solely because of differences in the voting schemes they use. More precisely, it analyses two interrelated problems: (i) how different voting algorithms, like those used in six independent central banks, affect how often active decisions are taken, and (ii) how effective these algorithms are in voting that is aimed at keeping inflation within target bands. Problem (i) is analysed in Section 2, which describes particular voting algorithms and presents the voting activity index for particular algorithms. Section 3 is devoted to problem (ii) and describes the settings of the simulation model that is used and presents the results under the assumption of purely random forecast signals delivered to voters. Section 4 concludes and discusses possible developments of the technique proposed.

\section{THE CONTESTANTS: MPC VOTING ALGORITHMS AND VOTING ACTIVITY}

It is assumed that there are $n$ members of an MPC voting at regular intervals at time $t$. All voters are sincere in the sense that their decisions are based solely on the outcome of their individual decision functions (see, e.g. Dietrich and List, 2004). The MPC voting always results in a decision $\Psi_{t}=-1,0$ or 1 , where -1 stands for a pro-inflationary measure such as a cut in the interest rate, 1 is an anti-inflationary measure like a rise in the interest rate, and 0 means the status quo is maintained. To define the particular voting schemes, the following notation is used.

Let $v_{i, t}$ denote the voting decision of the $i^{\text {th }}$ MPC member, $i=1,2, \ldots, n$, at time $t, t=1,2, \ldots, T$, to vote for the outcome $k=-1,0,1 . I_{i t}^{(k)}$ is its indicator function so that $I_{i, t}^{(k)}=1$ if $v_{i, t}=k$, and 0 otherwise. Further on, let us identify the indicator function of the MPC member with the casting vote as $I_{c, t}^{(k)}$ and denote the random variables that aggregate or count the votes as $I_{t}^{(k)}=\sum_{i=1}^{n} I_{i, t}^{(k)}$

. The particular voting mechanisms that can result in a decision $\Psi_{t}$ are:

1. The Federal Reserve Board (FED) voting scheme. In the FED scheme, one member of MPC is the Chair, who proposes a motion that is either supported by the majority, including the Chair, or is not. If the Chair proposes to maintain the status quo, so $\Psi_{t}=0$, it is uncontested. The voting decision is then:

$$
\Psi_{t}=\left\{k: \max \left(I_{t}^{(k)}\right)\right\} \times I_{c, t}^{(k)} .
$$


In this scheme, the number of voters, $n$, is equal to 12 for five Governors and seven nominated members.

2. The Bank of England (BoE) voting scheme $(n=9)$. The decision is equal to the median vote when the number of votes is odd, and to 0 if it is even, that is:

$$
\Psi_{t}=\left\{k: \sum_{\kappa<k} I_{t}^{(\kappa)}+\sum_{\kappa>k} I_{t}^{(\kappa)}=n-\sum_{\kappa=k} I_{t}^{(\kappa)}\right\} \times(-1)^{n} .
$$

3. The Bank of Sweden (BoS) voting scheme $(n=6)$. This is a three-way majority voting system voting, where the decision is taken by the majority of votes as $-1,0$ and 1 , with the Chair having a casting vote if there is a tie. The decision is defined as:

$\Psi_{t}^{\prime}=\left\{k: \max \left(I_{t}^{(k)}\right)\right\}$ and $\Psi_{t}=\Psi_{t}^{\prime}$ if $\Psi_{t}^{\prime}$ is a one-element set, meaning there is no tie, or:

$\Psi_{t}=\left\{\kappa: I_{c, t}^{\kappa}=1 ; \kappa \in \Psi_{t}^{\prime}\right\}$ if $|\kappa|=1$ and $\Psi_{t}=0$ otherwise.

4. The Bank of Canada (BoC) voting scheme $(n=6)$. This is a three-way majority voting scheme, but without a casting vote. If there is a tie, $\Psi_{t}=0$.

5. The Bank of Australia (BoA) voting scheme. The voting scheme is as in BoC, but $n=9$.

6. The Bank of Poland (BoP) voting scheme $(n=10)$. This is an absolute majority voting scheme such that the voters first vote for the $\Psi_{t}=1$ motion. If there is no absolute majority, or if there is a tie and the motion is not supported by the Governor, there is another vote for the $\Psi_{t}=-1$ motion. If the voting is not decisive, $\Psi_{t}=0$. Hence: $\Psi_{t}^{\prime}=\left\{k: \max \left[\left(I_{t}^{(k)} / n\right)-0.5\right]\right\}$ if $\left(I_{t}^{(k)} / n\right)>0.5$ and $\Psi_{t}^{\prime}=0$ otherwise. If $\Psi_{t}^{\prime}$ is a one-element set, meaning no tie, then $\Psi_{t}=\Psi_{t}^{\prime}$; otherwise $\Psi_{t}=\left\{\kappa: I_{c, t}^{\kappa}=1 ; \kappa \in \Psi_{t}^{\prime}\right\}$ if $|\kappa|=1$ and $\Psi_{t}=0$ if $\kappa=0$.

These voting algorithms are somewhat stylised and might not fully reflect the reality of voting. Firstly, it is difficult to find clear information on the scheme of how votes in individual central banks are aggregated. The settings given above are based on fragmentary information from the minutes and other documents of various central banks, and in some cases on private information. Secondly, some banks are quite liberal in applying the voting rules. There is some anecdotal evidence of voting on more than one motion simultaneously and of exceptional voting rules being applied. Consequently, the algorithms above should be treated as a somewhat arbitrary stylisation of the real voting processes.

It might be that all the six schemes described above result in different decisions being taken for the same set of extraneous information delivered to the voters. It is possible to evaluate how far each scheme tends to take active decisions, that is such that $\left|\Psi_{t}\right|=1$, by computing the voting activity index (VAI) by dividing the number of all possible active decisions by the total number of different combinations of decisions available to a given composition of each MPC. The complication for the $\mathrm{FED}, \mathrm{BoS}$ and $\mathrm{BoP}$ voting schemes is that assigning a casting vote to different MPC members affects the outcome as the caster might or might not influence the outcome, depending on the initial voting results and their own preferences. This is dealt with in computing the VAIs by assigning the casting vote to each MPC member in turn and averaging the results. Table 1 contains the computation results, with standard errors resulting from averaging the results for different casters in parentheses. It should be noted that the VAI does not depend on the way the individual voting decisions $v_{i, t}$ are formed. The decision-making from voting is described later, in Section 4. 
Table 1 indicates substantial differences between the voting activity patterns in different voting schemes. Not surprisingly, the most active scheme is the one with the smallest number of MPC members and with a casting voter, which is BoS, and the least active scheme is that with the largest number of voters, which is FED. Comparing $\mathrm{BoS}$ and $\mathrm{BoC}$ shows that having a caster increases the degree of voting activity by $15 \%$ on average. Of the two schemes that have the same number of voters and no caster, the BoE and BoA schemes, the three-way majority voting is more active than the median voter scheme. The relative influence of the caster on the outcome, measured by the standard deviation of VAI, is by far the highest for FED, where the results can vary by nearly $16 \%$ on average, depending on who is carrying the casting vote.

Table 1: Average voting activity index (VAI)

\begin{tabular}{|c|c|c|c|c|c|c|}
\hline & FED & BoE & BoS & BoC & BoA & BoP \\
\hline$n$ & 12 & 9 & 6 & 6 & 9 & 10 \\
\hline No. comb. & 91 & 55 & 28 & 28 & 55 & 66 \\
\hline Av. VAI & 0.474 & 0.546 & 0.768 & 0.571 & 0.618 & 0.538 \\
& $(0.157)$ & $(0)$ & $(0.038)$ & $(0)$ & $(0)$ & $(0.060)$ \\
\hline
\end{tabular}

To assess the interdependence of the voting schemes, simple Spearman's rank correlation coefficients have been computed for the paired outcomes of all the voting algorithms. A complication arises though because there is a different number of all possible outcomes when there is a different number of voters, and that makes direct pairwise comparison impossible. Consequently, we have computed the correlation coefficients for an equal number of voters assuming for each pair of algorithms, say $x, \mathrm{y}$, that the number of voters is equal first to that of $x$, and then to that of $y$. Table 2 presents these coefficients. The upper triangle shows the rank coefficients when the number of voters is that given in the second row of the table and the lower triangle for the number of voters given in the second column. Standard deviations resulting from assigning the casting vote to different voters are given in parentheses.

In Table 2, standard errors equal to zero appear when neither of the pair of algorithms compared has a caster or if the voting outcomes of both methods are identical and the correlation between the results is perfect. It is interesting to note that this happened to the BoE and BoP algorithms for $n=10$, so if Bank of England had 10 voters rather than nine, but not in the reverse situation if the Bank of Poland had nine voters rather than 10.

Table 2: Rank correlation coefficients for outcomes of different voting algorithms

\begin{tabular}{|c|c|c|c|c|c|c|c|}
\hline & \multirow{2}{*}{$n$} & FED & BoE & BoS & BoC & BoA & BoP \\
\cline { 2 - 7 } & 12 & 9 & 6 & 6 & 9 & 10 \\
\hline FED & 12 & & $\begin{array}{c}0.563 \\
(0.244)\end{array}$ & $\begin{array}{c}0.599 \\
(0.208)\end{array}$ & $\begin{array}{c}0.548 \\
(0.226)\end{array}$ & $\begin{array}{r}0.548 \\
(0.226)\end{array}$ & $\begin{array}{r}0.658 \\
(0.210)\end{array}$ \\
\hline BoE & 9 & $\begin{array}{c}0.592 \\
(0.266)\end{array}$ & & $\begin{array}{c}0.740 \\
(0.017)\end{array}$ & $\begin{array}{c}0.753 \\
(0)\end{array}$ & $\begin{array}{c}0.753 \\
(0)\end{array}$ & $\begin{array}{r}1.000 \\
(0)\end{array}$ \\
\hline BoS & 6 & $\begin{array}{c}0.616 \\
(0.145)\end{array}$ & $\begin{array}{c}0.675 \\
(0.044)\end{array}$ & & $\begin{array}{c}0.732 \\
(0.099)\end{array}$ & $\begin{array}{c}0.732 \\
(0.099)\end{array}$ & $\begin{array}{c}0.715 \\
(0.081)\end{array}$ \\
\hline BoC & 6 & $\begin{array}{c}0.523 \\
(0.127)\end{array}$ & $\begin{array}{c}0.819 \\
(0)\end{array}$ & $\begin{array}{c}0.732 \\
(0.010)\end{array}$ & $\begin{array}{c}0.090 \\
(0.0)\end{array}$ & $\begin{array}{c}0.758 \\
(0.098)\end{array}$ \\
\hline BoA & 9 & $\begin{array}{c}0.513 \\
(0.240)\end{array}$ & $\begin{array}{c}0.753 \\
(0)\end{array}$ & $\begin{array}{c}0.882 \\
(0.0101)\end{array}$ & $\begin{array}{c}1.000 \\
(0)\end{array}$ & $\begin{array}{c}0.789 \\
(0)\end{array}$ \\
\hline BoP & 10 & $\begin{array}{c}0.635 \\
(0.284)\end{array}$ & $\begin{array}{c}0.812 \\
(0.062)\end{array}$ & $\begin{array}{c}0.776 \\
(0.043)\end{array}$ & $\begin{array}{c}0.830 \\
(0.039)\end{array}$ & $\begin{array}{c}0.830 \\
(0.039)\end{array}$ & \\
\hline
\end{tabular}

The correlation coefficients are slightly higher for the pairs of algorithms compared where the number of voters is lower. The correlation of the outcomes of the FED algorithm with the others is generally lower than the correlation of outcomes for the other algorithms. 
Without further assumptions, it is not possible to decide whether the committees with more or fewer voters and more or less voting activity are better. That depends on the competence of the voters and the signals they receive. So in order to decide which voting algorithm leads to more accurate decisions, other things being equal, it is necessary to design a model that explains the mechanism of the decisions taken by individual committee members. Such a model is given in Section 3.

\section{HETEROGENEOUS VOTING MODEL AND FORECAST UNCERTAINTY}

The voting decisions $v_{i, t}$ in the schemes given in Section 2 are the outcomes of the decisionmaking process of the voters. The model describing these decisions is a modified version of that developed by Charemza and Ladley (2016). It is assumed that $n$ voting members of the MPC vote in each period $t=0,1,2, \ldots, T$. The decision function for the $i^{\text {th }}$ MPC member, $1 \leq i \leq n$, is derived as a solution of a simple optimisation problem of a Taylor-like decision function (see Geraats, 2009):

$$
z_{i}=\pi_{i, t+1}^{f}\left[\omega_{i}+\theta\left(1-\omega_{i}\right)\right],
$$

where $\pi_{i, t+1}^{f}$ denotes the level of inflation that the $i^{\text {th }}$ MPC member expects in time $t$ for time $t+1, \theta$ is a real sphere weight, and $\omega_{i}$ is the weight representing the individual tendency of the voter to favour active voting, so the higher $\omega_{i}$ is, the more the $i^{\text {th }}$ MPC member favours active decisions relative to the other members. The following rule describes voting decisions:

$$
v_{i, t}=\left\{\begin{array}{ccc}
1 & \text { if } & s_{i}^{+}<z_{i, t} \\
0 & \text { if } & s_{i}^{-}<z_{i, t}<s_{i}^{+} \\
-1 & \text { if } & s_{i}^{-}>z_{i}
\end{array},\right.
$$

where $s_{i}^{-}$and $s_{i}^{+}$are the lower and upper thresholds set a priori and assumed to be constant in time.

The expectations in the forecasts developed by the MPC members are interdependent in the sense that the vector $\left[\pi_{1, t+1}^{f}, \pi_{2, t+1}^{f}, \ldots, \pi_{n, t+1}^{f}\right]$ ' is generated from a multivariate normal distribution with identical covariances and variances equal to the variance of $\pi_{t+1}$, which is inflation in time $t+1$ and is assumed to be a random variable. In such a setting, all the bivariate correlation coefficients are identical and are equal to $r$. Consequently, an increase in $r$ means that the dispersion between the forecasts delivered to individual voters decreases. The concept of uncertainty by disagreement, proposed by Bomberger (1996) and developed further, by Giordani and Söderlind (2003), Lahiri and Sheng (2010), and Clements (2014) in particular, and in the context of its effect on monetary policy decisions by Charemza, Díaz and Makarova (2019), states that the dispersion of individual forecasts is a measure of uncertainty. As an increase in $r$ indicates a reduction in forecast uncertainty, uncertainty can be controlled for by manipulating $r$.

It is assumed that initially $\pi_{0} \sim N\left(\pi_{0}^{e}, 1\right)$ and it is further assumed that the only factor changing the distribution of inflation in times $t>0$ is the $M P C$ decision. More precisely:

$$
\pi_{t+1} \triangleq \pi_{0}-\sum_{j=1}^{t} \kappa^{\Psi} \Psi_{j} \quad, \text { for } t>0
$$

where $\stackrel{\wedge}{=}$ denotes equality in distribution, $\Psi_{t}=-1,0$ or 1 depending on the final voting decision of the MPC (see Section 2), and $\kappa$ is the decision strength, which is assumed to be constant 
over time. Depending on the outcome of earlier voting, the distribution of $\pi_{t+1}$ might be nonnormal and skewed.

It is convenient to interpret $s^{-}$and $s^{+}$as the lower and upper bounds for the inflation target, especially if the bounds are around zero, meaning the point inflation target $\pi^{T}=0$, and $s^{-}=-0.4307, s^{+}=0.4307$. The initial distribution of inflation is standard normal, so for $\pi_{0}^{e}=0$, this gives the probability of 0.333 of inflation being within the bounds at time 0 . Further assumptions used in the simulations are:

$$
\text { (i): } \omega_{i}=i / n ;(i i): \theta=0.25 ;(i i i) \kappa=0.25 \text {. }
$$

If there is no active decision about inflation in the model described above, so $\Psi_{t}=0$ throughout, the distribution of inflation remains unchanged over time for each $t$ and each voting algorithm and is equal to $\pi_{0}$. Only active voting causes inflation distribution to change. Hence in period $t=1,2, \ldots, T$, each of $n M P C$ members:

- computes (1), that is, solves the Taylor-like optimisation problem as described in Geraats (2009);

- makes a voting decision (2) based on the signal received for expected inflation;

- votes using one of the voting algorithms described in Section 2.

In period $t+1$ the distribution of inflation is decided by (3). In all settings $\pi_{i, t+1}^{f}$ are drawings from the inflation distribution in period $t+1$ that are mutually dependent with the correlation coefficient $r$, but independent of $t$, and are made under the assumption that the MPC decision would be passive. This is then the same as the distribution of inflation in time $t$. Rationally, if inflation in period $t+1$ is to be within the bounds of the inflation target, the best move would be to vote for no action and, if inflation in time $t+1$ is to be outside the bounds, an appropriate active decision will direct it towards the bounds. This is the essence of the aggregate measure of success in the voting contest used here, the ratio of deviations from target denoted as RDT, which was introduced by Charemza and Ladley (2016). It is computed as:

$$
R D T_{t}=1-\frac{\operatorname{Pr}\left(s^{-}<z<s^{+}\right)}{\operatorname{Pr}\left(s^{-}<\pi_{t}<s^{+}\right)},
$$

where $z \sim N(0,1)$. Recalling that $\pi_{0} \sim N\left(\pi_{0}^{e}, 1\right)$, and $s^{-}$and $s^{+}$are the lower and upper limits of the target bounds, $z$ is a hypothetical inflation distribution with dispersion that is never affected by voting and with the mean of the distribution in the middle of the inflation target. The distribution of $\pi_{t}$ might be non-trivial if any active voting took place in the past. Consequently, $\operatorname{Pr}\left(s^{-}<\pi_{t}<s^{+}\right)$is approximated by running 250,000 replications of the voting process for each period $t=1,2, \ldots, T$, and computing the frequency of cases where the inflation observation was within the inflation target. Clearly, a smaller $R D T_{t}$ means the probability of inflation being around the inflationary target is higher.

In order to account for different initial conditions, the mean of the initial inflation distribution changes from $\pi_{0}^{e}=-1$ to $\pi_{0}^{e}=1$ with a step of 0.05 . In the current setting, the planning horizon is equal to $T=5$, and the degree of correlation between the forecasting signals varies as $r=0.1$, 0.5 and 0.95 , which correspond to a high, moderate and low degree of forecast uncertainty.

Figures 1a-e give the pairwise comparisons of the $R D T_{t}$ s for the Bank of Poland with those of the other five central banks. Results for high uncertainty, represented by $r$, are in the upper 
panels, for moderate uncertainty in the middle panels and for low in the bottom panels. The plots show a similar pattern of the evolution of the $R D T_{t} \mathrm{~s}$ with the changes in the distance of inflation from its target for all the banks. The U-shape of the curves indicates that as this distance increases, the voting algorithms become less efficient at bringing inflation back to the target bands. The FED algorithm is slightly more efficient than that of the Bank of Poland at keeping inflation in time within the target band of \pm 0.4307 if $\pi_{0}^{e}$ was already within this band or close to it. However, as the distance of $\pi_{0}^{e}$ from zero increases, the advantage of the voting algorithm of the Bank of Poland becomes evident. This advantage decreases as forecast uncertainty decreases as $r$ increases. When uncertainty is low, the FED algorithm dominates that of the Bank of Poland for nearly all values of $\pi_{0}^{e}$ except the most extreme ones.

There is some asymmetry in the RDTs for the Bank of Poland for the positive and negative $\pi_{0}^{e}$ with the same module. Figure $1 \mathrm{~b}$ shows that this asymmetry is much greater for the Bank of England, for which the minimum point of the $R D T$ is not very close to $\pi_{0}^{e}=0$; it is to the right of it, with a tendency to drift to the right as uncertainty decreases. For $\pi_{0}^{e}>0$ and for cases where the negative expected value of initial inflation is moderate, the voting algorithm of the Bank of England is more effective at keeping inflation within the target bands than that of the Bank of Poland. For the more extreme cases of negative $\pi_{0}^{e}$, the voting algorithm of the Bank of Poland outperforms that of the Bank of England.

The voting algorithm of the Bank of Sweden (Figure 1c) is generally more effective than that of the Bank of Poland. The exception comes when uncertainty is high and $\pi_{0}^{e}$ is close to zero. The Bank of Canada algorithm (Figure 1d) is also more effective than that of the Bank of Poland for moderate and low uncertainty if $\pi_{0}^{e}$ is close to zero, meaning it is within the target bands. This result is similar to that for FED shown in Figure 1a. The result for the Bank of Australia (Figure 1e) is again asymmetric and is similar to that for the Bank of England.

Figure 2 presents a comparison of the RDTs for the Bank of Poland (Figure 2a) and FED (Figure $2 b)$ for the different forecast uncertainty, represented by different $r$ 's. The pattern for the Bank of Poland is similar to those of the Banks of England, Sweden, Canada and Australia, which are not reported here. As forecast uncertainty increases, the voting algorithms become more effective. It should be noted that in the schemes (1)-(3), where the forecasts are drawn randomly from a distribution with constant dispersion, a more certain forecast with a large $r$ might be just as wrong or right as a less certain forecast. Consequently, when there is little forecast uncertainty, and individual forecasts are relatively close to each other, voting algorithms are more likely to produce a wrong and hence ineffective decision. However, this is slightly different for FED. For a negative or slightly positive $\pi_{0}^{e}$, the pattern is the same as for the other algorithms. For markedly positive values of $\pi_{0}^{e}$, there are practically no differences between the RDTs for the different levels of uncertainty. 
Figure 1a: Comparison of $R D T$ 's, Bank of Poland and FED

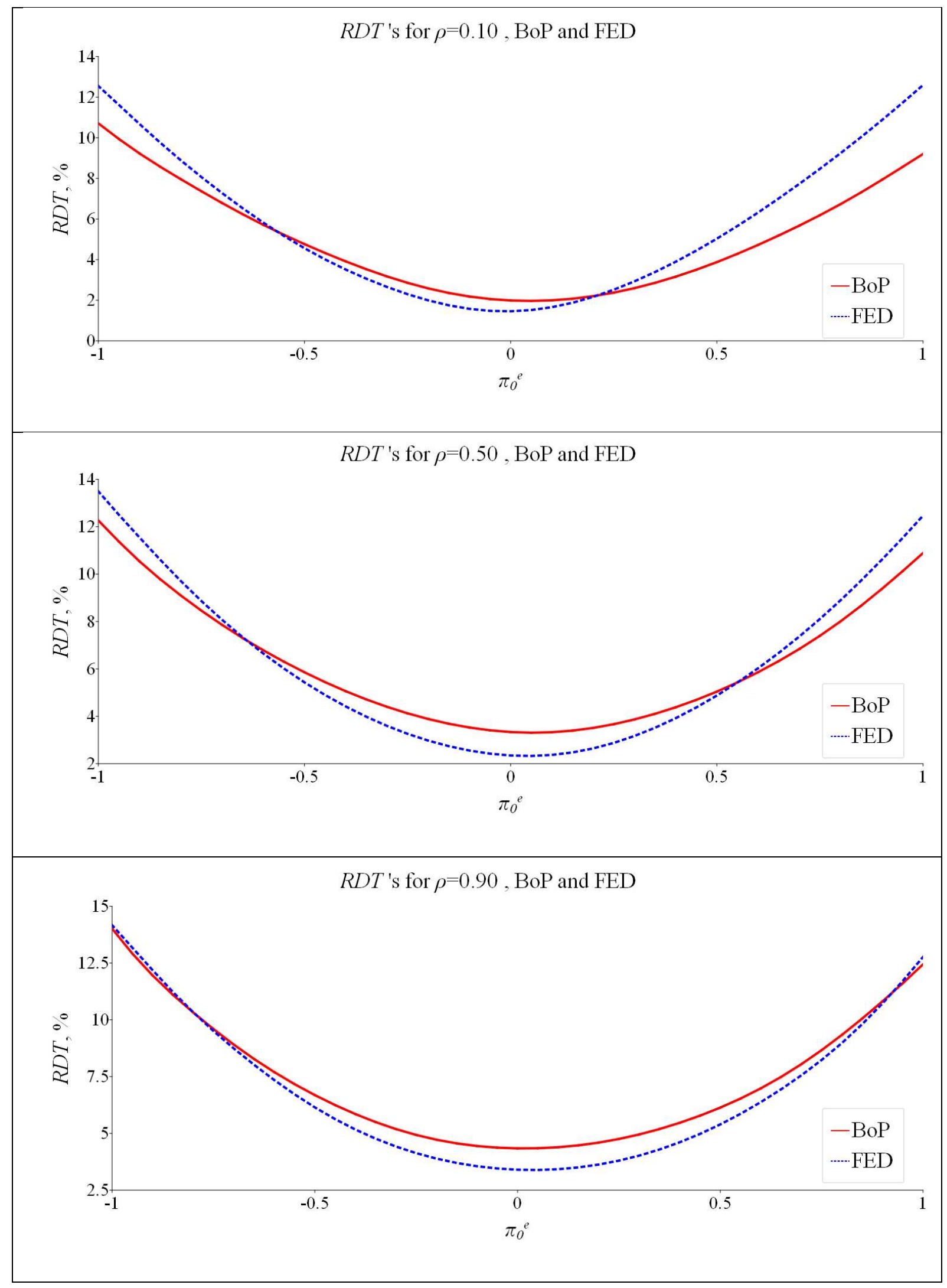


Figure 1b: Comparison of RDT's, Bank of Poland and Bank of England

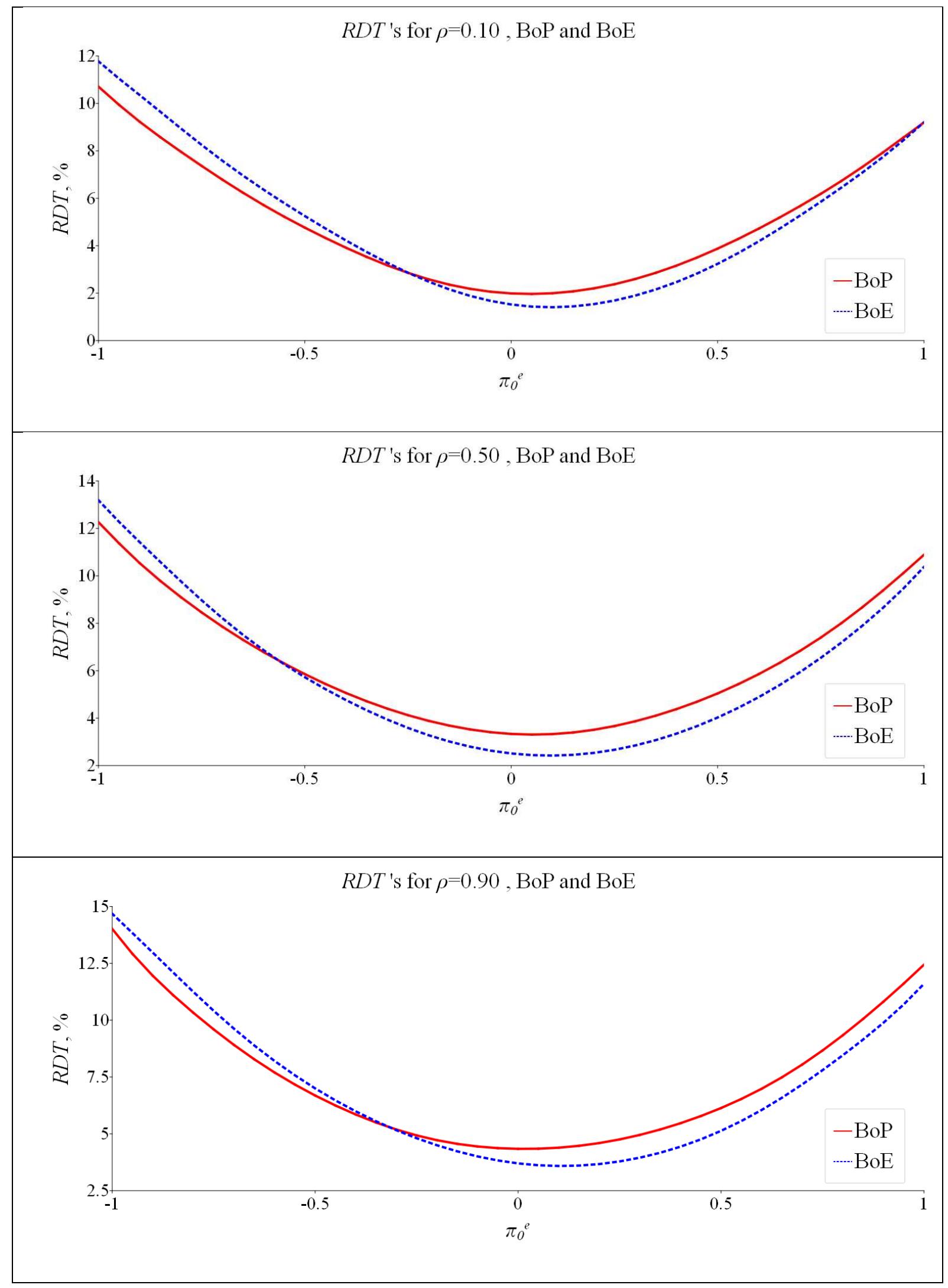


Figure 1c: Comparison of RDT's, Bank of Poland and Bank of Sweden

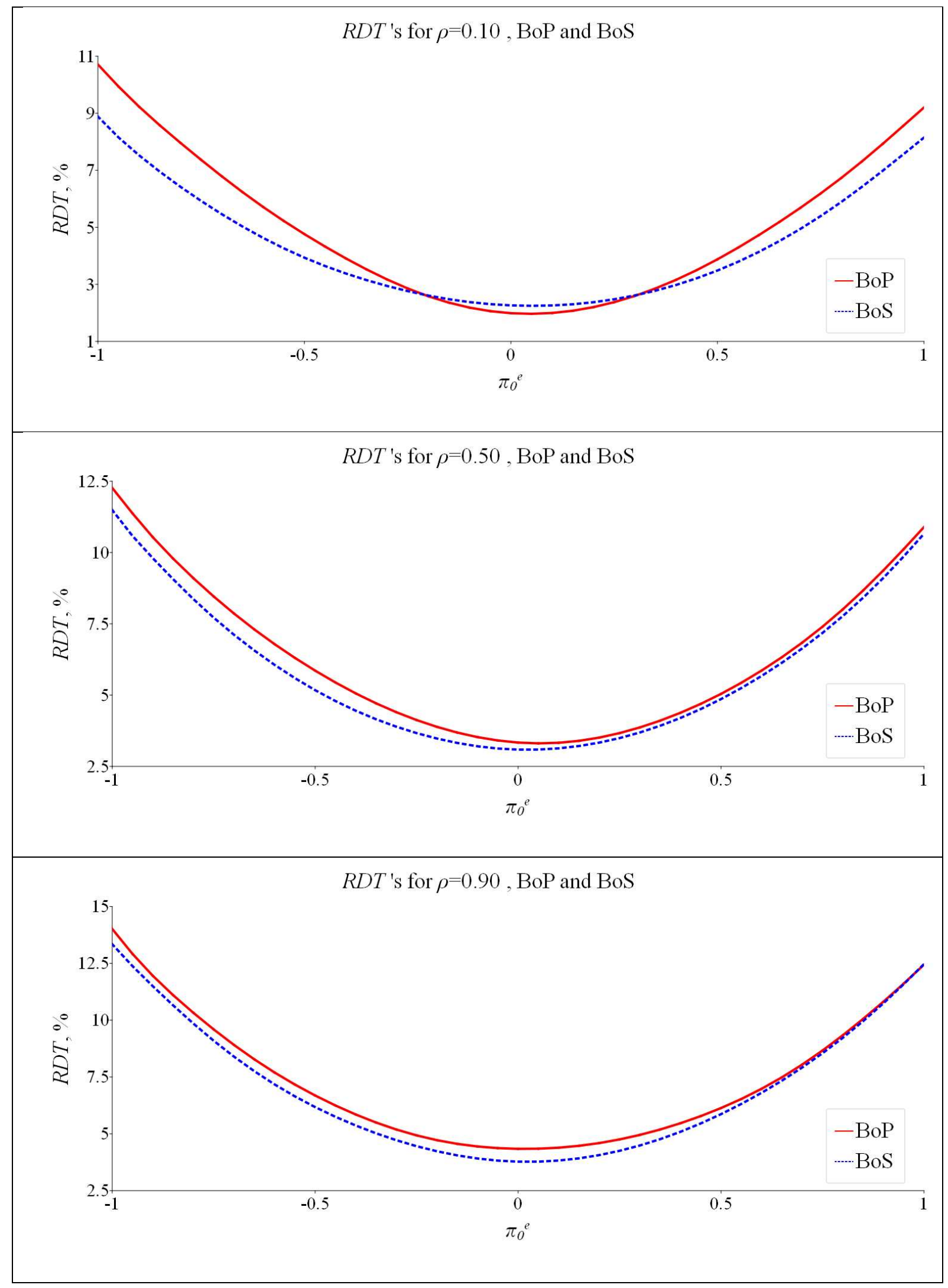


Figure 1d: Comparison of RDT's, Bank of Poland and Bank of Canada

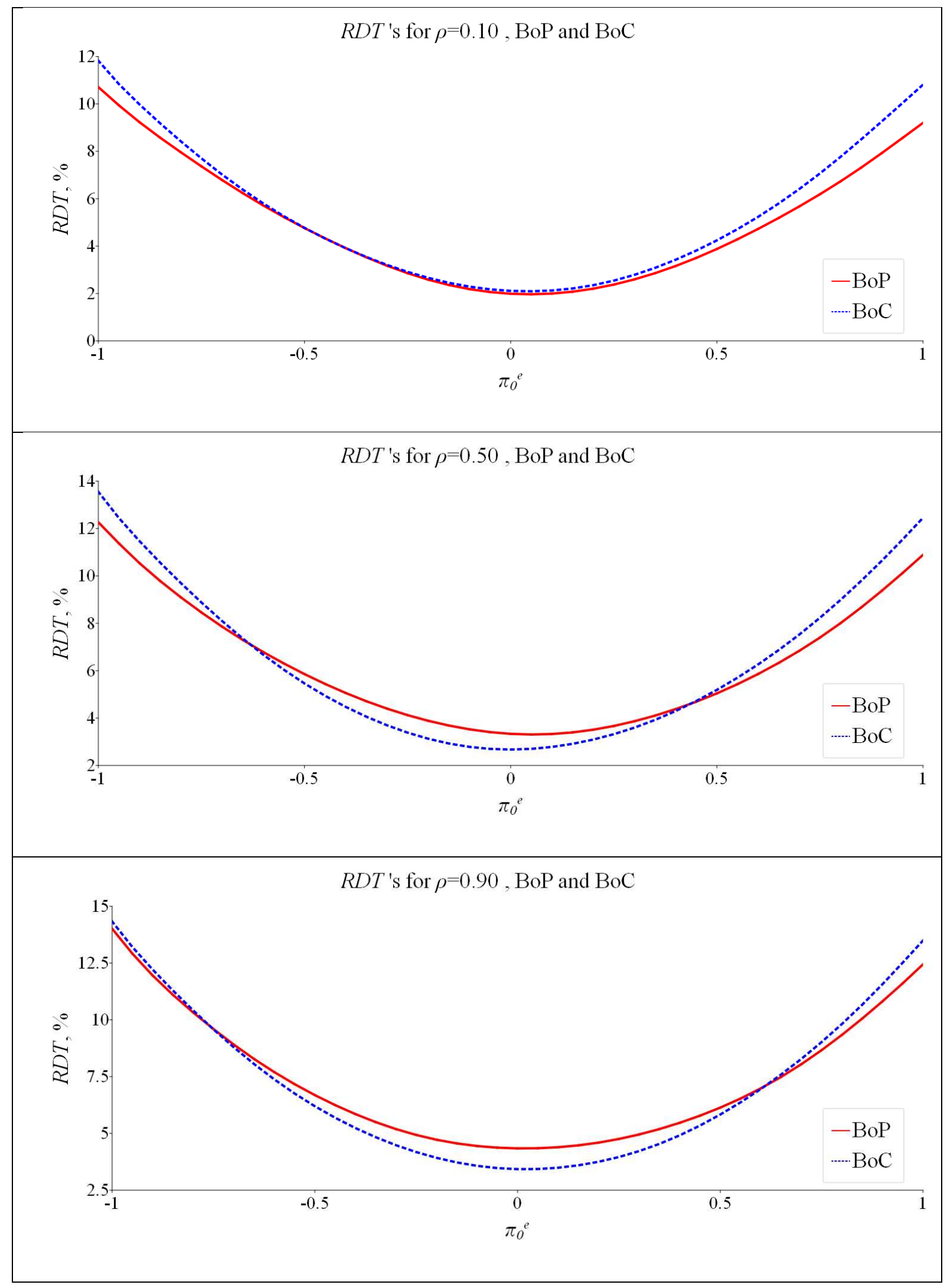


Figure 1e: Comparison of RDT's, Bank of Poland and Bank of Australia

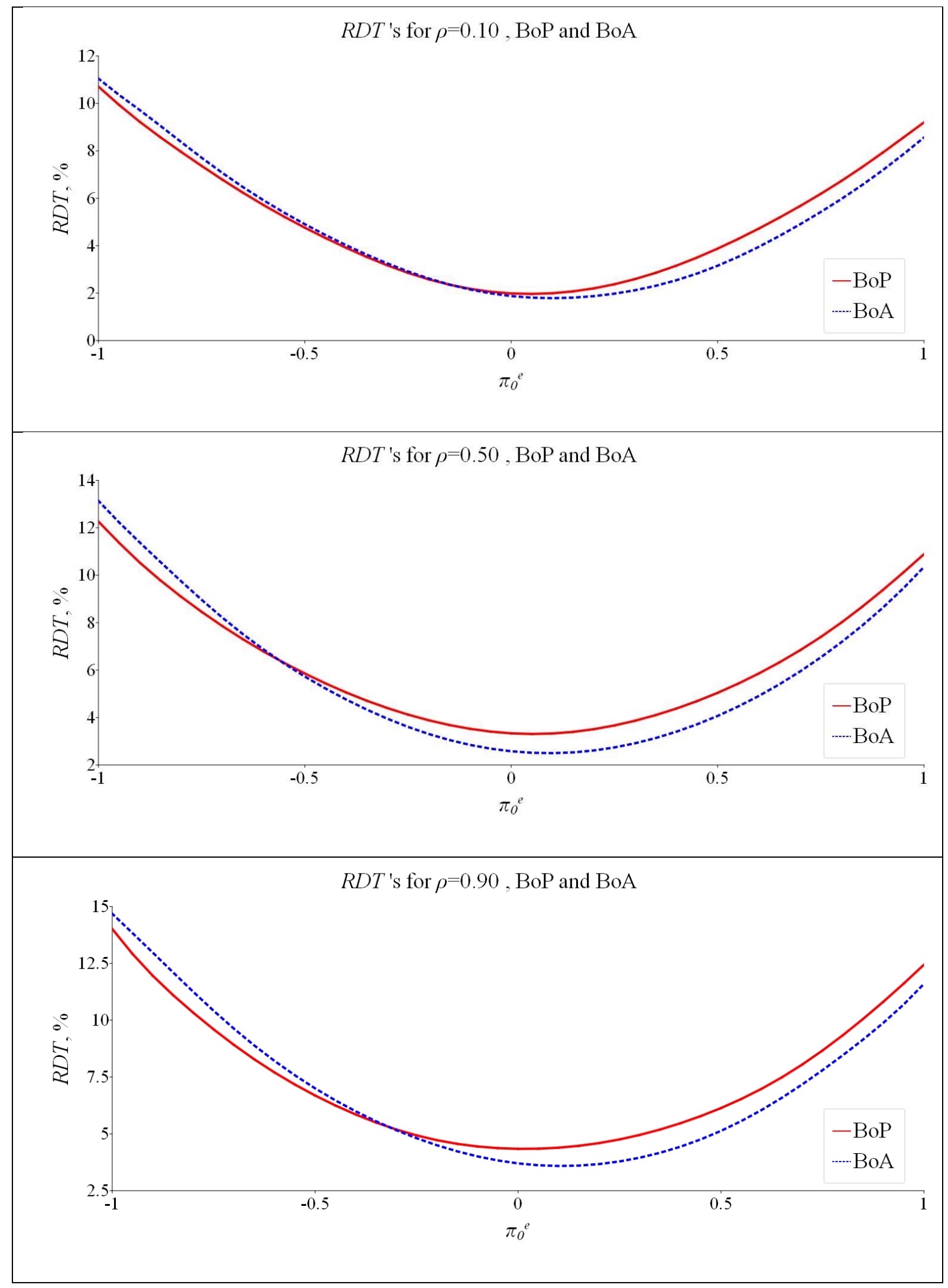


Figure 2a: Comparison of RDT's for different forecast uncertainty, Bank of Poland

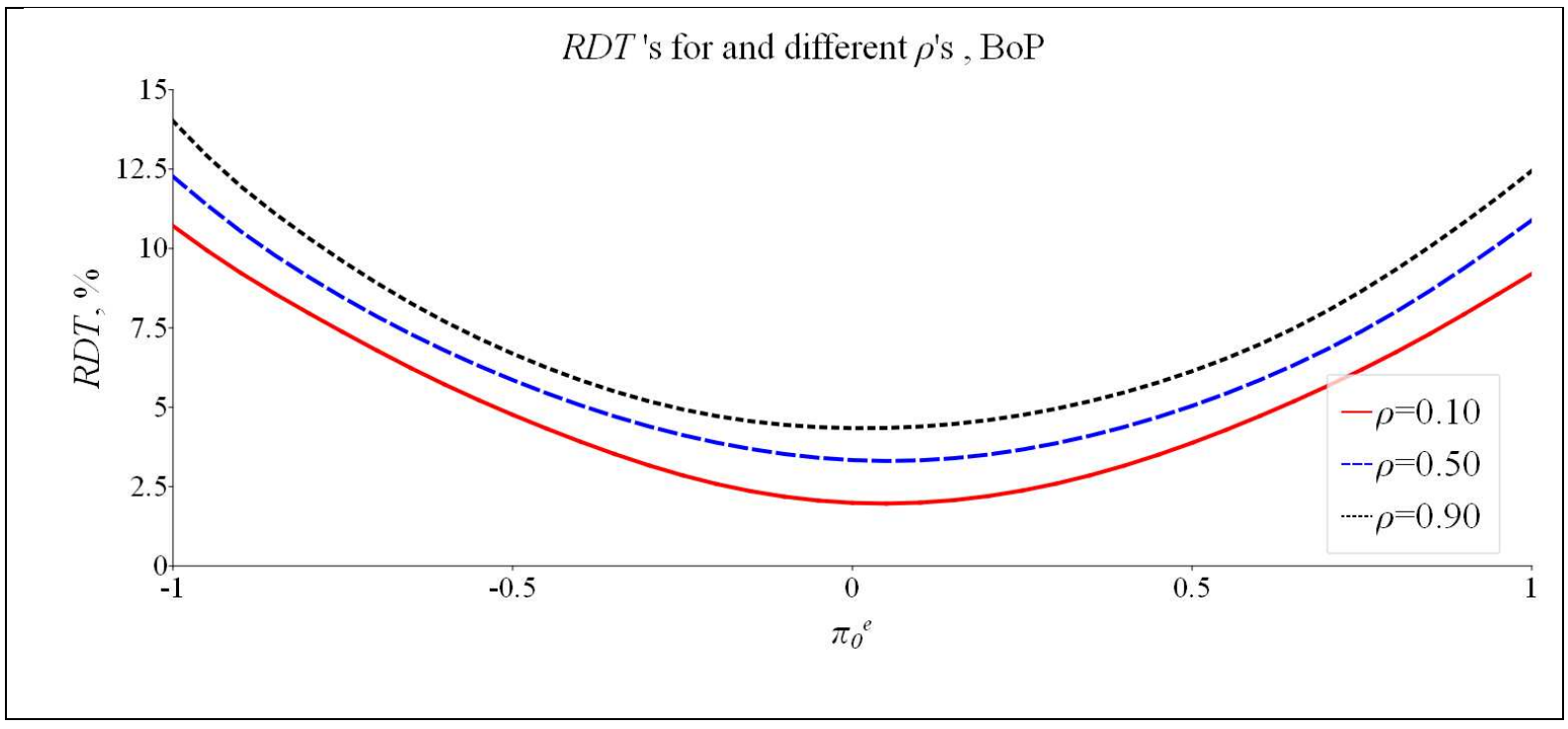

Figure 2b: Comparison of $R D T$ 's for different forecast uncertainty, FED

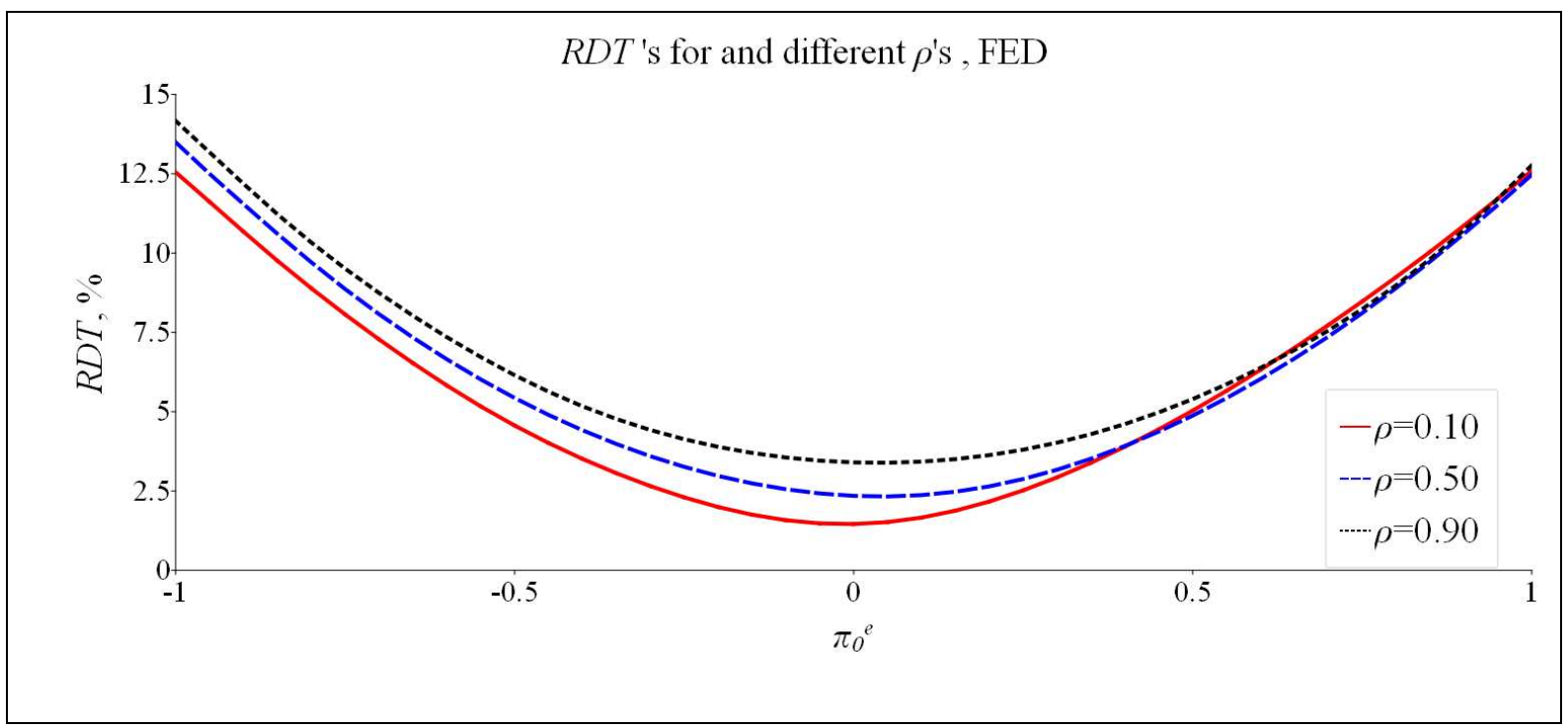

Figures 1 and 2 suggest a simple aggregate measure for comparing the efficiency of voting algorithms. Clearly, the most efficient algorithm on aggregate in the region $\pi_{0}^{e} \in \bar{\Pi}$ is the one for which the area below the $R D T_{t}$ curve is the smallest in this region. Numbering the algorithms as $j=1,2, . ., 6$, and denoting $R D T_{t}^{j}=f_{t}^{j}\left(\pi_{0}^{e}\right)$ for the continuous case, the best algorithm is the one where:

$$
j: \int_{\pi_{0}^{e} \in \bar{\Pi}} f_{t}^{j}\left(\pi_{0}^{e}\right) d \pi_{0}^{e}=\min
$$


As the measurements of $\pi_{0}^{e}$ are taken at identical intervals that are the same for all the algorithms, the integral above is proportional to the sum of the $R D T_{t} \mathrm{~s}$ for $\pi_{0}^{e} \in \bar{\Pi}$. For comparison we consider three subsets here: (1) $\left|\pi_{0}^{e}\right| \in[-0.4307,0.4307]$, so it is within the target area; (2) $\left|\pi_{0}^{e}\right| \in[0.4307,1]$, which is where the initial inflation is outside the target area; and (3) $\pi_{0}^{e} \in[-1,1]$, where the entire set of $\pi_{0}^{e}$ 's is under consideration. Table 3 presents these sums for all the algorithms compared and for the different $r$ 's.

Table 3: Sums of the RDTs for the six voting algorithms

\begin{tabular}{|c|c|c|c|c|c|c|c|c|c|}
\hline & \multicolumn{3}{|c|}{$r=0.05$} & \multicolumn{3}{c|}{$r=0.50$} & \multicolumn{3}{c|}{$r=0.95$} \\
\hline & $(1)$ & $(2)$ & $(3)$ & $(1)$ & $(2)$ & $(3)$ & $(1)$ & $(2)$ & $(3)$ \\
\hline FED & 36.21 & 201.9 & 238.1 & 47.44 & 208.9 & 256.4 & 63.50 & 219.5 & 283.0 \\
\hline BoE & 32.74 & 172.1 & 204.8 & 48.35 & 190.6 & 238.9 & 68.13 & 222.0 & 290.2 \\
\hline BoS & 42.10 & 139.6 & 181.7 & 57.67 & 183.9 & 241.5 & 70.34 & 217.4 & 287.7 \\
\hline BoC & 42.47 & 181.5 & 224.0 & 52.87 & 210.0 & 262.9 & 64.89 & 228.9 & 293.8 \\
\hline BoA & 36.82 & 160.4 & 197.2 & 49.26 & 190.4 & 239.6 & 68.13 & 222.0 & 290.2 \\
\hline BoP & 40.23 & 165.6 & 205.8 & 62.38 & 195.4 & 257.8 & 78.89 & 224.6 & 303.5 \\
\hline
\end{tabular}

Table 3 does not give an immediate and clear indication of the winner of the contest. Hence it seems convenient to summarise the results in another table showing the winners, with the smallest sum of $R D T_{t}$, and the losers, with the largest sum of $R D T_{t}$, for (1) the entire range of initial inflation, or $\pi_{0}^{e} \in[-1,1]$; (2) initial inflation being within the target bounds; and (3) initial inflation being outside the target bounds. The results are shown in Table 4.

Table 4: Winners and losers of the voting contest

\begin{tabular}{|l|c|c|c|c|c|c|}
\hline & \multicolumn{2}{|c|}{ entire range } & \multicolumn{2}{c|}{$\pi_{0}^{e}$ within target bounds } & \multicolumn{2}{c|}{$\pi_{0}^{e}$ outside target bounds } \\
\hline & $\begin{array}{c}\text { high } \\
\text { uncertainty }\end{array}$ & $\begin{array}{c}\text { low } \\
\text { uncertainty }\end{array}$ & $\begin{array}{c}\text { high } \\
\text { uncertainty }\end{array}$ & $\begin{array}{c}\text { low } \\
\text { uncertainty }\end{array}$ & $\begin{array}{c}\text { high } \\
\text { uncertainty }\end{array}$ & $\begin{array}{c}\text { low } \\
\text { uncertainty }\end{array}$ \\
\hline winners & BoS & FED & BoE & BoC & BoS & BoS \\
\hline losers & FED & BoP & BoS & BoP & FED & BoP \\
\hline
\end{tabular}




\section{CONCLUSIONS: AND THE WINNER IS ....}

The results given in Section 3 show that the voting algorithm of the Bank of Poland does not do very well against the criterion of being effective at keeping inflation within the target bands. It is particularly ineffective when forecast uncertainty is low, meaning when the forecast signals delivered to the individual voters are highly correlated. The overall winner is the voting algorithm of the Bank of Sweden, which uses three-way majority voting with six voters and a caster. It beats all the other algorithms in the most important case, which is where the initial expected value of inflation is outside the target bounds so that an active decision is needed to bring it back within those bounds. The results shown in Section 2 indicate that it is also the algorithm that, on average, gives active voting outcomes most frequently. However, it is less effective if the initial inflation is close to the target as it lies within the target bounds. This algorithm is also robust to changes in forecast uncertainty, as it is a winner both when uncertainty is high and when it is low. The algorithm with the most extreme results is that of the FED, which does well with low uncertainty, but fails when the uncertainty is high.

Caution is needed in interpreting these results. Firstly, just because the stylised Bank of Sweden algorithm performs better than the others at keeping inflation within the target in the simulation experiment described here does not mean that the Swedish monetary policy is superior. Conclusions should be strictly limited to the algorithms alone and not to the actual policies conducted. Secondly, although the experiment is numerically tedious and virtually impossible to conduct without a high-powered parallel computer, it is still limited in its scope. Only the extreme case of purely random forecasts has been described here. Further studies are needed for intermediate cases, where there is a certain degree of correlation between the forecasts and the outcomes. This is left for further investigation. 


\section{REFERENCES}

Akram, F., G. Bärsden, and Ø. Eithreim (2006),'Monetary policy and asset prices. Respond or not?', International Journal of Finance and Economics 1, 279-292.

Charemza, W., C. Díaz and S. Makarova (2019), 'Quasi ex-ante inflation forecast uncertainty', International Journal of Forecasting 35, 994-1007.

Charemza, W. and D. Ladley (2016), 'Central banks' forecasts and their bias: evidence, effects and explanation', International Journal of Forecasting 32, 804-817.

Choi, D.B., T. M. Eisenbach, and T. Yorulmazer (2016), 'Sooner or later: timing of monetary policy with heterogeneous risk-taking, American Economic Review: Papers \& Proceedings, 106, 490-495.

Clements M.P. (2014.) 'Forecast uncertainty - ex-ante and ex-post: US inflation and output growth', Journal of Business and Economic Statistics 32, 206-216..

Dietrich, F. and C. List (2004), 'A model of jury decisions where all jurors have the same evidence', Knowledge, Rationality \& Action, 142, 235-262.

Geraats, P. (2009), 'Trends in monetary policy transparency', International Finance 12, 235268.

Gersbach, H. and V. Hahn (2009), 'Flexible majority rules for central banks', Journal of Money, Credit and Banking 41, 507-516.

Gersbach, H. and B. Pahl (2009), 'Voting transparency in a monetary union', Journal of Money, Credit and Banking 41, 831-853.

Giordani, P. and P. Söderlind (2003), 'Inflation forecast uncertainty', European Economic Review 47, 1037-1059.

Horváth, R. and J. Jonášová (2015), 'Central banks' voting records, the financial crisis and future monetary policy’, European Journal of Political Economy 38, 229-243.

Horváth, R., K. Šmídková and J. Zápal (2016), 'Voting in central banks: Theory versus stylized Facts', B.E. Journal of Economic Analysis and Policy 20150227, 1-62,.

Lahiri, K. and X. Sheng (2010), 'Measuring forecast uncertainty by disagreement: the missing link', Journal of Applied Econometrics 25, 514-538.

Olivei, G. and S. Tenreyro (2007), 'The timing of monetary policy shocks', American Economic Review 97, 636-663.

Riboni, A. and F. Ruge-Murcia (2014), 'Dissent in monetary policy decisions', Journal of Monetary Economics 66, 137-154.

Sirchenko, A. (2011), 'Policymakers' votes and predictability of monetary policy', EUI Working Papers, Department of Economics, ECO 2011/05.

Sosnowska, H. (2013), Analysis of voting method used in the European Central Bank', Operation Research and Decisions 1, 75-86. 